\title{
O Espelho: Infopropaganda britânica para Portugal e para o Brasil durante a I Guerra Mundial
}

\author{
O Espelho: British propaganda for Portugal and Brazil during World War I
}

\author{
Helena Lima \\ Doutora, Professora Auxiliar do Departamento de Jornalismo e Ciências da Comunicação da Faculdade de Letras da \\ Universidade do Porto, Investigadora do Centro de Investigação Media \&Jornalismo (CIMJ). \\ $<$ hllima@letras.up.pt;hllima@gmail.com> \\ Jorge Pedro Sousa \\ Professor Catedrático, investigador da Universidade Fernando Pessoa e do Centro de Investigação Media \& Jornalismo. \\ $<$ hllima@letras.up.pt:hllima@gmail.com >
}

\section{RESUMO}

Cem anos passaram sobre o início da I Guerra Mundial, na qual intervieram países como Portugal e o Brasil. A imprensa, apelidada de "bala de papel", tornou-se, uma peça central na propaganda para a formação de correntes de opinião pró e contra a guerra. A imprensa ilustrada foi particularmente relevante nesse processo. Esta pesquisa tem por objetivo descrever a forma como a revista britânica ilustrada O Espelho, redigida em português e difundida em Portugal e Brasil, apresentou a I Guerra Mundial. Concluiu-se que a revista se apresentava como informativa, mas que os seus textos e imagens são propagandísticos e antigermânicos, o que se compreende sabendo-se que $\mathrm{O}$ Espelho foi uma das revistas ilustradas concebidas pelo War Propaganda Bureau para difundir universalmente os pontos de vista britânicos sobre o conflito.

Palavras-chave: O Espelho. Propaganda. Jornalismo.

\begin{abstract}
One hundred years have passed from the beginning of World War I, in which intervened countries as Portugal and Brazil. The press, dubbed "Paper Bullet", became a centerpiece in propaganda in favor and against war. The illustrated press was particularly relevant in this process. This research aims to describe how the illustrated British magazine O Espelho [The Mirror], written in Portuguese and widespread in Portugal and Brazil, presented the World War I. It was concluded that the magazine was presented as informative, but that their texts and images are propagandistic and anti-German, which is understandable given that $O$ Espelho was one of the illustrated magazines edited by the War Propaganda Bureau to universally spread the British points of view on the conflict.
\end{abstract}

Keywords: O Espelho [The Mirror]. Propaganda. Journalism.

\section{Introdução}

A deflagração da I Guerra Mundial intensificou a mobilização política em cada país interveniente. Os líderes políticos procuraram convencer os seus cidadãos da justeza da guerra, uni-los em torno de uma "causa nacional" e prepará-los para consentirem no sacrifício de vidas humanas. Ao longo da guerra, a propaganda encarregar-se-ia, assim, de agregar as pessoas em torno da causa belicista dos países, minando os próprios esforços de paz (Navarro e outros, 2005, p. 226-227). Martin Gilbert (2007, p. 13) diz mesmo que, entre 1914 
e 1918, se desenrolaram "duas guerras", uma militar e a outra "de propagandistas e idealistas, repleta de ambições e ideais políticos e territoriais". Mesmo os partidos socialistas, internacionalistas, aceitaram, na França, na Alemanha e na Grã-Bretanha, a linha política oficial dos governos e empenharam-se "numa escalada lealista" que se manteria até ao fim do conflito (Salvadori e outros, 2005, p. 524).

A propaganda organizada e sistemática fez-se sentir no interior dos países e nas frentes de batalha. Foi uma inovação na forma de fazer a guerra. Por isso, quando o conflito terminou, começou a pesquisa sobre a propaganda de guerra. Relembre-se, nomeadamente, a obra pioneira de Harold Lasswell, de 1927, Propaganda Technique in the World War. No livro, o autor sustenta que a propaganda na Grande Guerra foi um instrumento capaz de mudar as crenças, as atitudes e as ações dos visados, cunhando a metáfora das mensagens propagandísticas como "balas mágicas" capazes de produzir os mesmos efeitos reativos em todos os receptores.

A imprensa, justamente apelidada de "bala de papel", tornou-se, efetivamente, uma peça central na luta simbólica que se travou, nos vários países, em torno da formação de correntes de opinião pró e contra a guerra. A imprensa ilustrada, em particular, assumiu uma certa centralidade nesse esforço. Só em português foram publicadas, na França e na Inglaterra, três revistas ilustradas propagandísticas direcionadas a Portugal e ao Brasil: Portugal na Guerra (impressa na França sob o patrocínio do governo da União Sagrada, entre junho e novembro de 1917, dirigida por Augusto Pina, suspendida pelo governo sidonista); O Espelho (impressa na Inglaterra, da responsabilidade de uma instituição denominada The Brazilian Associated Press e, depois, The Brazil Press Association, com conexões ao War Propaganda Bureau) e A Guerra llustrada, tradução portuguesa da revista britânica em francês La Guerre Illustrée, publicada, sintomaticamente, em 1918, após a cessação da publicação da revista Portugal na Guerra.

A propaganda de guerra valeu-se de todos os meios ao seu alcance para alcançar o maior número possível de cidadãos, no interior de cada país ou na frente de combate. A propaganda britânica terá sido a mais eficaz durante a GrandeGuerra,já que era desenvolvida em segredo e insinuantemente, enquanto a propaganda alemã, ao basear-se, pomposa e abertamente, nos êxitos das suas tropas, sofreu sérios contratempos quando as derrotas começaram (Pizarroso Quintero, 1993).

Tendo em conta o contexto atrás delineado, a presente pesquisa tem por objetivo descrever a forma como a revista britânica O Espelho, redigida em 
português e difundida em Portugal e no Brasil, apresentou a I Guerra Mundial aos seus leitores. Procurou apurar-se que discurso foi esse, atendendo-se, em especial, aos significados que poderá ter produzido junto dos leitores e tendose em consideração quer o que se conhece do contexto histórico do período 1914-1918 quer o discurso da própria revista. A pesquisa apresenta, sistemática e quantitativamente, os conteúdos iconográficos d'O Espelho, e justifica a estrutura temática do discurso iconográfico da revista recorrendo aos textos sobre o Brasil publicados na própria revista. Estes textos foram encarados como dispositivos de contexto relevantes para a compreensão do discurso iconográfico d'O Espelho. Assumiu-se, nesta vertente do estudo da publicação, que as imagens publicadas pelo $O$ Espelho fazem parte de uma rede intertextual, surgindo, portanto, associadas à linguagem escrita.

\section{O Espelho e a propaganda de guerra britânica}

O Espelho foi uma revista ilustrada britânica de grande formato (cerca de $30 \times 40 \mathrm{~cm}$, um pouco maior do que uma folha A3) e de 16 páginas, editada em Londres, desde setembro de 1914, por uma entidade designada The Brazilian Associated Press, cuja denominação foi alterada, no número de 15 de dezembro de 1915, para The Brazil Press Association. Embora direcionada para Portugal e para o Brasil, a revista visava, especialmente, o público brasileiro, conforme a denominação da entidade proprietária deixa transparecer.

A designação O Espelho encerrava, toda ela, uma promessa: a de "espelhar" a Grande Guerra. Aliás, na capa dos primeiros números $O$ Espelho proclamou que seria um "fiel espelho" da guerra, até porque contaria com a colaboração dos fotógrafos do Daily Mirror e, por isso, publicaria as "melhores e mais vividas fotografias tiradas no local dos acontecimentos". O tema é enfatizado na penúltima página do número 1, numa advertência ao leitor: "O Espelho dispõe do trabalho do corpo de fotógrafos do Daily Mirror, atualmente no campo de ação, e publicará as mais vividas fotografias dos importantes acontecimentos da guerra, em terra, nos mares e nos ares" (O Espelho, 1914, p. 15). A revista lucrava, assim, com a ideia do senso-comum de que as fotografias não mentem porque são espelhos de particularidades da realidade. Razão tem, pois, Pizarroso Quintero (1993) quando afirma que a propaganda britânica era insinuante. A revista efetivamente insinuava ao leitor que não seria mais do que um espelho do que se passava na Grande Guerra, quando, na verdade, a sua razão de ser terá sido a propaganda do ponto de vista oficial britânico perante a conflagração.

Os conteúdos d'O Espelho referem-se principalmente, à marcha da guerra, em especial aos êxitos reais ou imaginados dos britânicos e aos insucessos reais 
ou imaginados da Alemanha e dos seus aliados, às novas táticas e equipamentos, aos socorros e apoio aos feridos de guerra e à "batalha da produção" de material de guerra a nível interno. O design d'O Espelho era arejado. Tinha bastante espaço branco - repousante para o olhar - a rodear palavras e imagens, até porque beneficiava do grande formato. Embora inicialmente tivesse incluído páginas coloridas, $O$ Espelho depois ficou- pelo preto-e-branco.

N'O Espelho, o espaço consagrado às imagens é relevante. Em vários números, por exemplo, foram incluídas ilustrações em dupla página; noutros, encontram-se páginas ocupadas por uma única imagem, incluindo, constantemente, as primeiras páginas; ou com duas; ou até mesmo com seis (no máximo). As fotografias e gravuras, porém, não eram de produção própria, mas sim de outros periódicos britânicos, como The Graphic, The Sphere, The Illustrated London News e Daily Mirror, e também de fotógrafos portugueses, como Arnaldo Garcês, um dos pioneiros do fotojornalismo português, que, integrado no exército com a patente de alferes, cobriu a preparação das tropas portuguesas e o seu posicionamento na frente de batalha. A revista também publicou fotos "oficiais" (ou seja, dos serviços militares de propaganda de guerra), identificadas como sendo Official Photographs - Press Bureau, e, entre outras, fotografias de pessoas famosas fornecidas por casas fotográficas como a Lafayette Ltd. Interessantemente, a partir de junho de 1915, O Espelho intensificou o recurso às ilustrações - mais dramáticas - das revistas ilustradas The Graphic e The Sphere, em detrimento das fotografias do Daily Mirror e dos serviços militares. É de assinalar, portanto, que havia uma enorme circulação intertextual de conteúdos (textos, gravuras e fotografias), quer entre as revistas ilustradas britânicas, quer mesmo entre estas e as revistas de outros países aliados, como a llustração Portuguesa, que usou, entre outras, gravuras e fotografias da Illustrated London News, do Graphic e da Sphere (Sousa, 2013).

\section{Infopropaganda iconográfica}

Considerou-se, nesta análise, que as imagens de finalidade informativa, enquanto signos propõem ao recetor, no contexto de uma determinada cultura, visões de significado compreensível de determinados aspectos do mundo, mas apurar o que cada imagem significa exatamente para cada receptor pode ser controverso. Reconheceu-se, em acréscimo, que, no jornalismo, as imagens são obtidas, selecionadas e editadas por um conjunto de intervenientes, eventualmente à luz de critérios de noticiabilidade ou outros nem sempre claros (Traquina, 2002), o que dificulta o desvelamento das intenções dos emissores. 
Contabilizaram-se para esta pesquisa todas as imagens dos números d'O Espelho existentes nas bibliotecas públicas portuguesas, o que permitiu constituir um corpus de 2.418 imagens, repartidas por fotografias, desenhos alusivos a acontecimentos e outras imagens (mapas, cartoons, reproduções de pinturas, diagramas, tabelas iconográficas, infografias explicativas, desenhos alusivos à moda e outros desenhos não alusivos a acontecimentos). Realce, desde logo, para uma primeira constatação: com exceção das imagens de prisioneiros das Potências Centrais e de combates e das imagens com destruição ou captura de equipamento do inimigo, todas as imagens analisadas respeitaram aos Aliados ou a potências neutrais que os Aliados queriam cativar (caso de Portugal e do Brasil antes de intervirem na Grande Guerra).

O Espelho publicou essencialmente dois tipos de imagem alusivos aos acontecimentos: fotografias e desenhos ilustrativos alusivos a acontecimentos. Embora menos icônicos, e, portanto, menos verosímeis do que as fotografias, os desenhos ilustrativos podem ter maior carga dramática do que as imagens fotográficas e o seu potencial narrativo, isto é, o potencial para ajudarem a contar e a compreender uma história, é maior. O recurso às gravuras faculta, ademais, ao desenhador, contar visualmente uma história como quer, com maior ou menor respeito pela realidade. No início do século XX, uma fotografia podia mentir, fosse pelo enquadramento selecionado, fosse pela composição, fosse pelos processos de edição (de manipulação, no sentido estrito de ser manipulada, i. e., processada). Mas, no limite, um desenho ilustrativo podia ser totalmente inventado, o resultado da pura imaginação do desenhador.

Quadro 1- Estrutura do discurso iconográfico d'O Espelho - tipo de imagens

\begin{tabular}{|c|c|c|}
\hline $\begin{array}{c}\text { Desenhos alusivos } \\
\text { a acontecimentos }\end{array}$ & Fotografias & Outras imagens \\
\hline $7,4 \%$ & $85,4 \%$ & $7,2 \%$ \\
\hline
\end{tabular}

Fonte: Os autores

O tema forte da iconografia d'O Espelho foi à representação da Grande Guerra. A revista recorreu, em especial, a fotografias ou desenhos, da ação militar (cf. apêndice gráfico) com $42 \%$ de todas as imagens, quase metade do total. A guerra era o tema do momento e o tema que a propaganda britânica pretendia explorar. Por outro lado, eram essas as imagens que proporcionavam mais intensidade dramática e narrativa à cobertura. Muitas das ilustrações 
relativas aos combates, inclusivamente, foram publicadas em duplas páginas, 0 que lhes dava um enorme impacto visual.

$O$ discurso iconográfico d'O Espelho foi também estruturado em torno dos retratos das personalidades dos países Aliados e dos países neutrais (cf. apêndice gráfico), ou pré-neutrais, e das imagens - especialmente fotografias - de paisagens e de edifícios (cf. apêndice gráfico), categorias nas quais foram contabilizadas, em ambas, $11 \%$ das imagens. A revista procurou demonstrar visualmente que os países Aliados tinham à sua frente líderes políticos e militares determinados e capazes de os guiar a porto seguro. Já as imagens de paisagens e de edifícios e monumentos foram usadas como artifício para permitir ao leitor contemplar, mediadamente, os espaços referidos nos textos e, frequentemente, expor o "barbarismo" alemão, que "nada pouparia".

Com as imagens da vida civil (cf. apêndice gráfico), que constituem 10\% do total da amostra, os responsáveis editoriais d'O Espelho terão procurado, por um lado, diversificar a cobertura, sintonizando a revista com a vida de todos os dias familiar ao leitor; por outro lado, importou-lhes transmitir a ideia de "um povo em armas" e demonstrar que os britânicos, mesmo em tempo de guerra, estariam a vencer a "batalha da produção", sendo capazes quer de fornecer às suas tropas o equipamento militar de que necessitavam quer de alimentar o seu povo, tudo isto no meio da maior tranquilidade cívica, havendo tempo para eventos sociais, para as artes e mesmo para a moda feminina (tática editorial destinada a cativar a atenção e o interesse do público feminino). Mais ainda, interessou a $O$ Espelho demonstrar que os britânicos investiam sem receio em títulos de guerra, animando, eventualmente, investidores estrangeiros a fazer o mesmo. Aliás, a publicidade d'O Espelho incluía vários anúncios relativos ao investimento em obrigações do tesouro dos países Aliados.

A categoria de imagens que se segue numa hierarquia de representatividade é a "Ação política e político-militar" (cf. apêndice gráfico), na qual se contabilizaram $6 \%$ de todas as imagens da amostra. De forma geral, incluíram-se nesta categoria todas as imagens relativas à interação entre militares e civis, normalmente destinadas a documentar a liderança efetiva em tempo de guerra, tranquilizando os espíritos, e a evidenciar que os líderes políticos estavam próximos dos militares em armas, com os quais colaborariam estreitamente, e do povo. As imagens dos "Socorros aos feridos de guerra" (cf. apêndice gráfico), com 5\%, além de documentarem uma realidade do conflito, sugerem, do ponto de vista positivo, que nenhum combatente seria abandonado à sua sorte. Para suscitarem comoção nos leitores e apelarem à sua solidariedade, denunciando, ao mesmo tempo, a "barbárie" germânica, os 
editores d'O Espelho usaram imagens de "Destruição e dano provocados pelo inimigo". Essas imagens também evocam a natureza brutal da Grande Guerra.

Já a categoria "Destruição e dano provocados ao inimigo" (cf. apêndice gráfico), na qual se classificaram $4 \%$ de todas as imagens que constituíram a amostra (entre as quais - obviamente - não se encontraram imagens de refugiados, mortos e feridos inimigos nem de destruição dos seus monumentos), apelam à ideia de vitória.

É interessante notar que entre a iconografia d'O Espelho abundam os mapas e as infografias (cf. apêndice gráfico). Estes demonstram que a revista procurou explicar a guerra - desde o ponto de vista britânico - explorando as potencialidades expressivas, expositivas e esclarecedoras desse tipo de informação visual.

\section{O Brasil: a questão da neutralidade e o combate à influência alemã}

É reconhecida a importância da propaganda na I Guerra Mundial, nomeadamente pelo papel crescente que a palavra impressa ganhou desde os finais do século XIX. A industrialização da imprensa e o consumo de notícias por uma imensa audiência conferiram um papel central à palavra escrita, ao mesmo tempo em que se acreditava na sua total capacidade de influenciar e moldar o pensamento dos leitores, nomeadamente pela grande proliferação da imprensa popular (Marquis, 1978). A influência sobre a opinião pública tornou-se um dos eixos centrais da Grande Guerra, de tal forma que a par do conflito bélico, outra batalha igualmente decisiva se viria a desenrolar no campo da palavra.

A propaganda alemã parece ter tido uma estratégia muito mais focada nos já simpatizantes das causa germânica, sem procurar ganhar as boas graças dos povos de outros países, mesmo daqueles que assumiram uma posição de neutralidade face ao conflito. Nesse sentido a propaganda alemã foi vista como ineficiente e muito aquém da campanha levada a cabo pelos Aliados, como, aliás, foi reconhecido posteriormente (Hitler; Ludendorff citados por Rosenbush, 2013).

Os Aliados, e em particular, a Inglaterra desenvolveram um esforço sistemático na tentativa de seduzir as nações com posições neutrais, através da combinação de diversas técnicas de persuasão:

A operação britânica com base em Wellington House, em Londres, usou diversos meios, incluindo a agência de notícias Reuters, para atingir o público-alvo em todo o mundo. Sir Gilbert Parker, que tinha grande familiaridade com a América, dirigiu o trabalho voltado para 
os Estados Unidos. Sua técnica foi apropriadamente caracterizada por James Squires como sendo um 'namoro suave' versus um'cortejar violento'. Foi sutil, discreto e altamente eficaz. Programas britânicos de desinformação também foram especificamente voltados para a Alemanha' (Murphy e White, 2007, p. 16).

Este modelo aqui apontado para a opinião pública americana parece adaptar-se aos textos presentes no $O$ Espelho. Globalmente, o discurso pode ser classificado como um namoro constante dirigido aos leitores da língua portuguesa, onde o tom elogioso abrange as nações, a história, os povos ou as personalidades mais destacadas. Paralelamente, o outro lado da construção ideológica caracteriza-se pela demonização da Alemanha, das suas práticas, intenções e cultura pan-germanófila.

Ingleses ealemães tiveram uma perspectiva diferentedopapeldaimprensa na "guerra das palavras", decorrente do próprio modelo histórico de cada um dos países. No caso germânico, os jornais tinham evoluído sob um aparelho repressor e censório que no período da guerra facilmente integrou o discurso oficial. Pelo seu lado, a imprensa britânica desenvolveu-se num enquadramento de liberdade de expressão, o que "obrigou" as autoridades britânicas a criar um modelo alternativo, que não contrariasse esta tradição. Ainda assim, os jornais ingleses acabariam por assumir a causa dos Aliados, sem que fosse necessário impor um modelo censório, ao mesmo tempo em que jornalistas e empresários da imprensa eram seduzidos por várias iniciativas das autoridades (Marquis, 1978). É neste enquadramento de discurso cuidadosamente construído, onde a sedução das palavras dirigida aos leitores de português se combina com a violência dos ataques à causa germânica, que podemos entender o conteúdo d'O Espelho, enquanto publicação primorosa ao serviço da propaganda britânica. Para além da qualidade das imagens, a revista alia a qualidade dos textos, de teor muito diversificado, publicados segundo uma lógica informativa. No período aqui em análise (1916-1918), registra-se uma grande variedade de temáticas, que vão desde as diferentes frentes de guerra até aos protagonistas, numa abordagem mais global, até aos artigos mais direcionados para a opinião pública do Brasil e Portugal. A dimensão do tratamento de cada uma das matérias é igualmente muito variável, registrando-se a inclusão de temas de

1 Tradução nossa de: The British influence operation based at Wellington House in London used several means, including the Reuters news agency, to reach target audiences worldwide. Sir Gilbert Parker, who had wide familiarity with America, directed the work targeted at the United States. His technique was aptly characterized by James Squires as being a "gentle courtship" versus a "violent wooing." It was subtle, understated, and highly effective. Specific British disinformation programs were also aimed directly at Germany 
fundo e por vezes com sequência em vários números, mas também informação mais breve, em parágrafos, agrupada numa das últimas páginas e separada por grafismos. A média de textos publicados por número é bastante variável, com alguns que apresentam apenas quatro, até aos números finais de 1918, em que se podiam incluir dez ou mais artigos.

Em termos dos textos focados em temas relacionados com o Brasil, a variedade da dimensão é igualmente patente, dependendo do tipo de enquadramento escolhido. Os assuntos que remetem para aspectos mais fatuais implicavam em regra um tratamento noticioso mais relacionado com o acontecimento e, portanto os textos são mais concisos, remetendo para a relação objetiva noticia/ fato, típica do formato jornalístico.

Um grupo de textos centra-se muito nos aspetos da neutralidade. Em regra o tom é persuasivo, particularmente em relação ao Brasil, justamente pela necessidade de sedução enunciada anteriormente. "Portanto, foi nos países neutros, onde os esforços diplomáticos das partes em conflito se desenvolveram cara-a-cara, que a propaganda se tornou uma guerra de propaganda, com o objetivo de influenciar as mentes indecisas" ${ }^{\prime 2}$ (Marrero, 2013, p. 15). De fato, não bastava persuadir, era ainda necessário combater e neutralizar o discurso do inimigo, e O Espelho usou o tema da neutralidade brasileira, nesse sentido. De uma maneira geral a posição brasileira é elogiada e revelando ao mesmo tempo uma preocupação com as dificuldades econômicas resultantes do prejuízo que a guerra e em particular a guerra naval levada a cabo pelos alemães impuseram ao comércio colonial. Assim, O Espelho condena o "criminoso procedimento" alemão, que levou os países sul-americanos à ficarem desprotegidos devido à sua neutralidade face ao conflito (O Espelho, 1916, p. 4).

A ideia de honra associada aos países neutrais é várias vezes referida no discurso d'O Espelho e no caso do Brasil, a "amizade e aliança" é igualmente referida como uma prática constante entre as duas nações, por oposição às práticas germânicas que obrigavam ao rompimento da neutralidade absoluta. Este teria sido o caso do abastecimento dos navios alemães com carvão em portos brasileiros, mas também os casos de ataques marítimos contra embarcações civis.

As relações de cordialidade entre o Brasil e a Grã-Bretanha surgem em diversos artigos ao longo da publicação fosse o tema da neutralidade o aspecto central ou não. Tal é o exemplo de "O que se diz do Brasil na Inglaterra"(O Espelho,

2 Tradução nossa de: "Therefore, it is in the neutral countries where the diplomatic efforts of the warring parties came face to face, and where propaganda became a war of propaganda aiming to sway undecided minds in their own favor." 
1916, p. 4,), “O Brasil e a Inglaterra” (O Espelho, 1916, p. 2), “José Veríssimo imensa perda para as Letras Brasileira. Morte de um Amigo dos Aliados" (O Espelho, 1916, p. 3), “Os neutros e a paz" (O Espelho, 1916, p. 180), "Recepção na legação do Brasil em Londres", (O Espelho, 1916, p. 291). Nestes artigos, o(s) autor (es) mantém um tom elogioso da neutralidade brasileira, do carácter e da honra, que os britânicos respeitavam e encaravam com "simpatia". As relações são descritas como cordiais e a atitude dos brasileiros em relação aos ingleses era retratada como "sentimento de amizade", "cordialidade", "gentileza", "afectuosidade", "hospitalidade". A revista apelaria ainda à comunidade inglesa residente no Brasil para estabelecer laços mais estreitos e tentar melhor entender o ponto de vista do país, procurando ao mesmo tempo defender os produtos britânicos.

Apesar do "namoro" que a adjetivação revela, um artigo seria particularmente duro para com os países que se mantinham a margem do conflito:

\begin{abstract}
Não têm direito de intervir no momento da vitória final dos Aliados, aqueles que nos dias angustiosos da invasão, quando os bandidos germânicos talavam os campos da Bélgica e da França, incendiavam as bibliotecas e templos, desonrando virgens, ultrajando esposas, massacrando crianças, não tiveram um gesto sequer em favor da civilização conspurcada, em prol da humanidade sacrificada pelos bárbaros Teutões (Carvalho, 1916, p. 180).
\end{abstract}

Este texto, assinado por Reis de Carvalho, salvaguarda, contudo, a neutralidade brasileira, que defende estar do lado dos Aliados graças à sua intelectualidade e à Liga Brasileira dos Aliados, que desde 1915 se manifestou a favor da causa. O papel assinalável desta Liga foi igualmente referido em diferentes artigos e circunstâncias, pela importância da sua atividade em prol da aliança anglo-francesa.

A questão do comércio vem normalmente associada aos problemas da guerra e o impacto que esta teve nas economias sul americanas, mas também os artigos sobre os produtos coloniais das colônias portuguesas revelam a preocupação com que os britânicos viam este problema, nomeadamente pela escassez do café que se fazia sentir na Europa, como é patente no artigo "O café brasileiro" (O Espelho, 1917, p. 164). Curioso é também o texto que procura explicar aos brasileiros como devem rentabilizar a cultura da borracha, sendo este um extrato de um livro intitulado The rubber industry of the Amazon and how it supremacy can be mantained (O Espelho, 1916). O texto escrito em inglês, para além dos aspetos técnicos, aponta também para os efeitos nefastos que a 
doutrina Monroe norte americana tinha sobre a economia brasileira, o que não deixa de ser curioso do ponto de vista da diplomacia britânica.

Com o afundamento dos navios comerciais Paraná e Tijuca pelos alemães, os textos da neutralidade deram lugar a um discurso bastante mais incisivo. Em 21 de abril de 1917, o autor começa por fazer um longo intróito elogioso do governo de Wenceslau Braz e só após um conjunto de considerandos recupera a questão da reação brasileira aos ataques marítimos. Para o autor, estes seriam apenas a antecipação do inevitável fim da neutralidade, face às investidas alemãs ao comércio marítimo e à imposição da zona de bloqueio: "Deixar-se ficar neutro, depois das ignomínias de que os alemães se ufanam, constituía uma manifestação de desprezo pelos países da Entente. E, colocar-se assim indiretamente ao lado da Alemanha contra esses países seria uma grande vergonha" (O Espelho, 1917, p. 52). Este texto ilustra bem a combinação dos dois formatos discursivos em que se começa por um sedutor elogio, mas se passa a um enquadramento bastante mais duro para com os alemães, mas agora também abrangendo as debilidades da neutralidade, que em vários pontos do artigo é apontada como uma posição ao lado do Bloco Central. No artigo "A rutura das relações diplomáticas", também de 21 de abril 1917, a mudança de tom é também constatável e a estratégia discursiva é idêntica. Começa igualmente por rasgados elogios a Lauro Severiano Muller, que é descrito como homem de rasgo político e brilhantismo, destacando a sua coerência e honra face ao ataque alemão. Este ministro brasileiro é apontado como o responsável pela rutura das relações com a Alemanha, mas também da procura de uma ação concertada da América Latina no apoio à participação dos Estados Unidos na guerra, movimentação diplomática que colocava o Brasil como líder deste bloco de países, dando assim continuidade à tradicional doutrina Monroe. Apesar do elogio, é reconhecido que Muller tinha sido um dos defensores da neutralidade brasileira, o que contraria o espírito do texto anterior, e que acaba por ser uma espécie de antevisão da sua renúncia ao Ministério de Assuntos Exteriores. A segunda parte do artigo é ainda mais um discurso elogioso a outra personalidade brasileira, Fontoura Xavier, chefe da diplomacia do país, em Londres.

A importância do ministério responsável pelas relações internacionais seria de novo realçada com a nomeação de Nilo Peçanha. O artigo "O novo ministro do Exterior do Brasil", de 2 de junho de 1917, é o contraditório do que anteriormente foi afirmado em relação a Muller. Um das afirmações mais taxativas referentes ao novo ministro prende-se com o fato de as suas posições não serem ambíguas: 
A situação atual exigia, pelo menos na direcção dos negócios exteriores, um homem que já tivesse publicado sem subterfúgios e inteira convicção o seu pensamento inteiro sobre essa mesma situação. (...) a diplomacia do momento é de jogo franco e cartas na mesa (O Espelho, 1917, p. 100).

Num tom completamente diferente do artigo anterior, aqui elegia-se igualmente Peçanha pela sua crença na democracia como sistema político, mas também como intérprete da opinião pública brasileira: “Dado bom combate aos inimigos da Democracia, o Dr. Nilo Peçanha representa bem o pensamento da Nação inteira" (O Espelho, 1917, p. 100). É sabido que esta afirmação não corresponde completamente à verdade, já que as comunidades de origem alemã não se reviam neste posicionamento.

Uma das estratégias comunicacionais d'O Espelho está em linha com estes exemplos aqui referidos. Assim, a publicação opta por inserir artigos que sendo centrados em figuras públicas, têm indiretamente a ver com a política diplomática brasileira, jogando com a imagem que essas personalidades tinham junto da opinião pública. Nesse sentido, a personalidade política que detém maior destaque é, sem dúvida, Ruy Barbosa, estando o seu nome em título de vários artigos, mas usando também os seus discursos como forma de fundamentar a causa aliada em temáticas diferentes. O discurso de Ruy Barbosa proferido aquando das comemorações do Centenário da Argentina, por exemplo, foi publicado durante uma série de números da revista, o que espelha bem a importância da sua ação diplomática, para a causa dos Aliados na América do Sul.

A propaganda difundida pel'O Espelho é, pois uma construção onde se combinam várias técnicas discursivas, em que os textos podem incidir mais sobre a mensagem positiva, tendo como base figuras de referência da opinião pública brasileira ou os bons atos governativos, exemplos culturais, etc. ou podem assumir vertente destrutiva acentuada, quando se refere aos alemães e seus aliados. Esta abordagem negativa da causa alemã foi utilizada na imprensa britânica, em que as representações podiam combinar até oito técnicas negativas: estereótipos, nomes pejorativos, seleção e omissão de fatos, histórias de atrocidades, slogans, afirmações enviesadas, grandes derrotas censuradas, processos identificativos do inimigo e o "efeito onda" de solidariedade (Marquis, 1978, p. 486). Na revista O Espelho estas representações dos alemães estão também presentes, de uma forma parcelar nas diferentes referências encontradas, mas que adquirem uma maior sistematização num conjunto de artigos extraídos da obra de Raul D’Arcanchy, "A Germanização do Sul do Brasil“. 
Publicado intermitentemente, o tema da comunidade germânica que vivia nos estados do sul do Brasil, mas em particular em Santa Catarina, vai constituir uma bandeira essencial da propaganda negativa contra a causa alemã. Embora os diferentes aspectos se repitam em termos temáticos, há alguns eixos discursivos que revelam uma maior preocupação por parte do autor. Desde logo, o tom do texto geral retirado da leitura é de preocupação ao mesmo tempo em que procura alertar a opinião pública brasileira para os perigos que se escondem naqueles estados.

D'Arcanchy repete muito a ideia da manutenção de uma comunidade germânica fechada a influências externas, em que os colonos da primeira e gerações seguintes se mantêm alheios à miscigenação. Estas comunidades não só não se misturam com as outras, como preservam os valores políticos e culturais e a língua, que é ensinada nas escolas, em detrimento do português, particularmente em Santa Catarina. Nas escolas alemãs, as crianças aprendiam os valores, a língua, mas também a considerar os brasileiros intrusos, dando assim origem a gerações sucessivas de "súbditos alemães", que constituíam a "árvore sinistra cuidadosamente adubada", com a total indiferença das autoridades brasileiras (O Espelho, 1916, p. 122).

Uma dos argumentos que sustenta esta unidade cultural é a escrita, já que em escolas, informações das autoridades locais e mesmo nos jornais de propaganda, em que o alemão era o idioma utilizado. Um dos exemplos dados é o de um artigo de Rudolff Troppmair, director do Deutsche Zeitung für Rio de Janeiro, que acusava os brasileiros de subserviência aos ingleses e atribuindoIhes um termo muito insultuoso (Troppmair, 1916). Da mesma forma, o autor acusa os jornais catarinenses de serem partidários do pangermanismo: num texto extraído de um boletim não identificado, mas assinado pelos "Teutões", é reiterada a ideia da supremacia germânica e a certeza da vitória:

\footnotetext{
A Alemanha vencerá e então virá o ajuste de contas entre alemães e luso-brasileiros, principalmente em Santa Catarina. O Brasil quer aparecer à Europa como uma nação adiantada, mas quem o conhece intimamente sabe que o Brasil é um dos países mais atrasados do globo, infectado pela politicagem, pelas roubalheiras, pela indolência, e todas as más qualidades que trazem em si o gérmen da decadência [...](O Espelho, 1916, p. 138).
}

Incitava os colonos alemães a aguardarem a recuperação do lugar que Ihes cabia de direito, mas que Ihes tinha sido sonegado "infamemente pelos lusos, graças a um sistema eleitoral desonesto" (O Espelho, 1916, p. 138). 
Este autor refere ainda várias vezes uma conspiração para criar um estado único na América do Sul, sob protetorado alemão. A pedra angular desses Estados Unidos do Sul seria a constituição de um exército, de que o treino militar dado a chilenos sob o comando do coronel alemão Körner, seria a primeira iniciativa. Contudo, a sua preocupação ia sobretudo para expansão colonial germânica, assente em 500.000 colonos e descendentes, bem como as milícias de colonos alemães do sul do Brasil, que segundo D’Arcanchy, tinham treino militar e estariam bem armadas e dispostas a integrar o exército colonial alemão (O Espelho, 1916).

\section{Considerações finais}

Ao atentar na produção discursiva d'O Espelho, pode afirmar-se que esta se apresentou como uma revista jornalística, mas foi, como outras, uma revista de infopropaganda, que se serviu da informação e da argumentação para construir mensagens propagandísticas. Efetivamente, $O$ Espelho, sob o pretexto de difundir informação sobre acontecimentos e problemas concretos, disseminou propaganda. Propagou - propagandeou - uma visão enviesada da Grande Guerra - a visão que interessava ao poder britânico, recorrendo, em texto e imagens, a mensagens simples e verosímeis, persuasivas e argumentativas, e muito pouco a mensagens verdadeiras ${ }^{3}$ ou, a mensagens que dessem conta da enorme complexidade de fatores que estava em jogo na Grande Guerra. É notória, em particular, a apresentação maniqueísta e simplista da Grande Guerra como uma questão de nós, os bons, os britânicos e seus aliados (incluindo-se aqui os brasileiros germanófobos) contra eles, os bárbaros militaristas e imperialistas alemães, os traiçoeiros teutões, alguns deles habitantes de um Brasil que alinhava com a causa dos Aliados.

A partir da leitura d'O Espelho adquirir-se-ia, pois, em Portugal e no Brasil, uma visão enviesada da Grande Guerra. A visão moldada e desejada pela propaganda britânica. Seria essa visão aceite? Se o era, dificilmente o seria por todo o público. Na verdade, apesar dos meios colossais ao seu dispor para intervir na criação de correntes de opinião, em Portugal e no Brasil (país onde, inclusivamente, viviam bastantes descendentes de alemães) a propaganda britânica era contrabalançada por outros canais de comunicação, formais e informais. As mensagens propagandísticas britânicas competiam com uma infinidade de outras mensagens que iam chegando ao público. Apesar das

3 Entendendo-se aqui o conceito de verdade discursiva como a adequação do que é dito à realidade objetiva que existe independentemente do sujeito. 
dificuldades, já que os protagonistas morreram, pesquisa posterior poderia tentar, por via indireta, averiguar as circunstâncias da receção e da negociação de sentido, por parte da audiência, para as mensagens difundidas pela infopropaganda britânica no Brasil e em Portugal.

\section{Referências}

A REAÇÃO do Brasil. A louvável conduta do Governo Wenceslau Braz. O Espelho, Londres, 21 abr. 1917, p. 51-52.

CARVALHO. Reis de. Os Neutros e a paz. O Espelho, Londres, 12 ago. 1916, p. 180.

D'Arcanchy, Raul. A Germanização do Sul do Brasil. O Espelho, Londres, 3 jun. 1916, p. $86-87$; 17 jun. 1916, p. 122; 1. jul. 1916, p. 138-139; 15 jul. 1916, p. 156-157; 29 jul. 1916, p. 173.

GILBERT, M. A Primeira Guerra Mundial. Lisboa: Esfera dos Livros, 2007.

JOSÉ VERÍSSIMO imensa perda para as Letras Brasileira. Morte de um Amigo dos Aliados. O Espelho, Londres, mar. 1916, p. 3.

LASSWELL, H. Propaganda Technique in the World War. Cambridge: The MIT Press, 1971.

MARQUIS, A. G. Words as Weapons: Propaganda in Britain and Germany During the First World War. Journal of Contemporary History, v. 13, n. 3, 1978, (467-498). Disponível em: <http://www.jstor.org/stable/260205?origin=JSTOR-pdf >. Acesso em: 24 jan. 2014.

MARRERO J. P. Under Propaganda Fire: Spain and the Great War. Proceedings War and propaganda in the XXth Century. (13-18). In: Rollo, Maria Fernanda, Pires, Ana Paula \& Novais, Noémia Malva (Eds.). (2013). War and propaganda in the XXth Century [Electronic Document]. Lisboa: IHC, CEIS20. Disponível em: <file:///C:/ Users/ranielle/Downloads/War\%20and\%20Propaganda\%20in\%20the\%20 XXth\%20Century.pdf>. Acesso em: 14 jan. 2013.

MURPHY D. M.; WHITE J. F. Propaganda: Can a Word Decide a War? Parameters, posted in Small Wars Journal, (p.15-27), 2007. Disponível em: <http://smallwarsjournal. com/blog/parameters-autumn-2007>. Acesso em: 14 fev. 2012.

NAVARRO, F. (dir.) e outros. História Universal. v. 19. Lisboa: Salvat, Promoway e Público, 2005.

O BRASIL e a Inglaterra. O Espelho, Londres, fev.1916, p. 2.

O CAFÉ brasileiro. O Espelho, Londres, 28 jul. 1917, p. 164. 
O NOVO MINISTRO do Exterior do Brasil, O Espelho, Londres, 2 jun. 1917, p. 100.

O QUE se diz do Brasil na Inglaterra". O Espelho, Londres, jan. 1916, p. 4.

PIZARROSO QUINTERO, A. História da Propaganda Política. Lisboa: Planeta Editora, 1993.

RECEPÇÃO na legação do Brasil em Londres. O Espelho, Londres, 18 nov. 1916, p. 291.

O ESPELHO. Londres: The Brazilian Associated Press/The Brazil Press Association, 19141918. Mensal [periodicidade irregular]. Revista em acervo público.

O ESPELHO. Londres, set. 1914, p. 15.

O ESPELHO. Londres, jul; 1916, p.138, 156.

ROSENBUSH, A. Por la patria y por la verdad - Germany's effort to maintain Spanish neutrality during the First World War. (19-26). In: Rollo, Maria Fernanda, Pires, Ana Paula \& Novais, Noémia Malva (Eds.). (2013). War and propaganda in the XXth Century [Electronic Document]. Lisboa: IHC, CEIS20. Disponível em: $<$ file:///C:/Users/ranielle/Downloads/War\%20and\%20Propaganda\%20in\%20 the\%20XXth\%20Century.pdf >. Acesso em: 14 jan. 2013.

SALVADORI, M. L. (coord.) e outros. História Universal. Vol. 14. Lisboa: Planeta de Agostini e Cofina, 2005.

SOUSA, J. P. A Grande Guerra - Uma Crónica Visual (Parte I): Estudo do Discurso em Imagens da llustração Portuguesa (1914-1918). Sobre a Participação Portuguesa na I Guerra Mundial. Lisboa: Media XXI, 2013.

THE RUBBER industry of the Amazon and how it supremacy can be mantained $\mathbf{O}$ Espelho, Londres, fev. 1916, p. 2.

TRAQUINA, N. (2002): Jornalismo. Lisboa: Quimera, 2002.

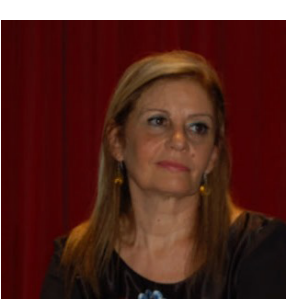

Recebido em: 19/6/2016

Aceito em: 20/6/2016

Endereço dos autores:

Helena Lima hllima@letras.up.pt;hllima@gmail.com

Departamento de Jornalismo e Ciências da Comunicação da Faculdade de Letras da

Universidade do Porto

Via Panorâmica, s/no

4150-564 - Porto - Portugal

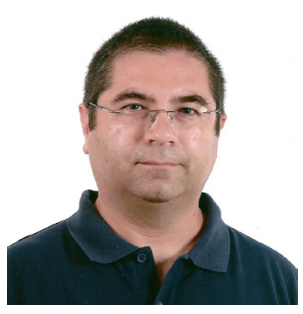

Jorge Pedro Sousa jpsousa@ufp.edu.pt; jorgepedrosousa@gmail.com

Universidade Fernando Pessoa

Praça 9 de Abril, 349

4249-004 - Porto - Portugal 
Apêndice gráfico
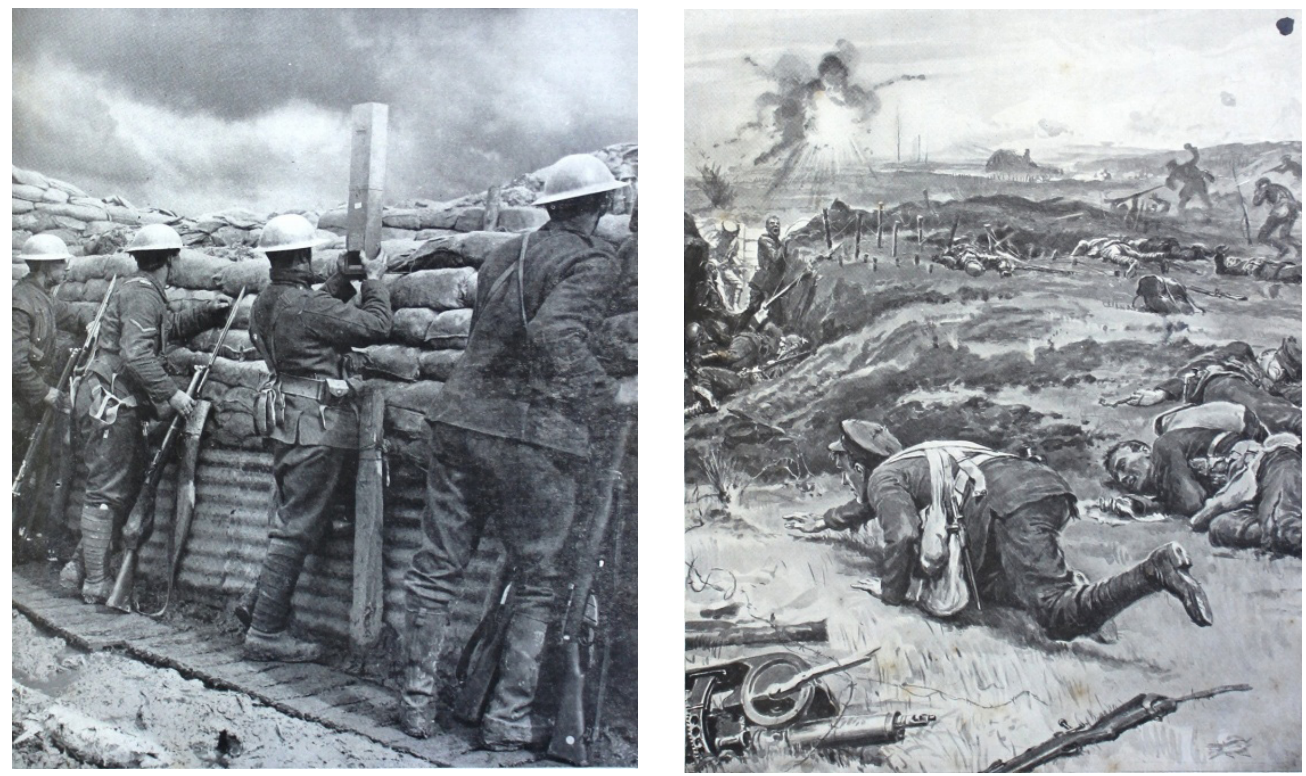

Figs. 1 e 2 - Imagens como estas foram contabilizadas na categoria "Ação e equipamento militar e pessoal militar". Representam, maioritariamente, cenas do quotidiano militar e de ações militares dos britânicos. Os desenhos foram muito usados para as representações das ações militares, não só porque não abundariam fotografias de ação (e as que existiam eram muitas vezes retidas pela censura) mas também porque neles o desenhador poderia intensificar quer a carga dramática quer o potencial narrativo, tentando levar o leitor a acreditar numa narrativa povoada de contínuos sucessos - reais ou imaginários - das forças britânicas. Os desenhos foram publicados originalmente na revista Sphere.

Fonte: O Espelho, mai. 1916, p. 1; fev. 1916, p. 1. 


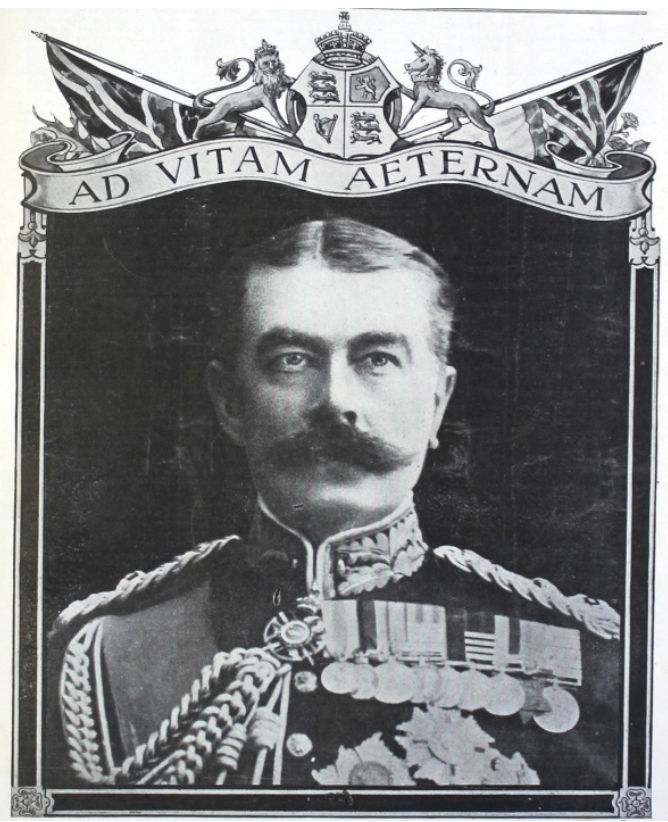

Fig. 3 - Os retratos dos líderes dos países Aliados tiveram uma presença assídua nas páginas d'O Espelho, contribuindo para atribuir rostos aos nomes e para mitificar as suas personalidades e a sua heroicidade. Imagens como esta, de lorde Kitchener, imponente no seu uniforme, ostentando as suas muitas medalhas, com uma expressão determinada, sugerem, aliás, que com tais líderes a vitória seria apenas uma questão de tempo. A comunicação social, na Grande Guerra, foi, neste sentido, uma fábrica simbólica de heróis. Fonte: O Espelho, 10 jun. 1916, p. 97

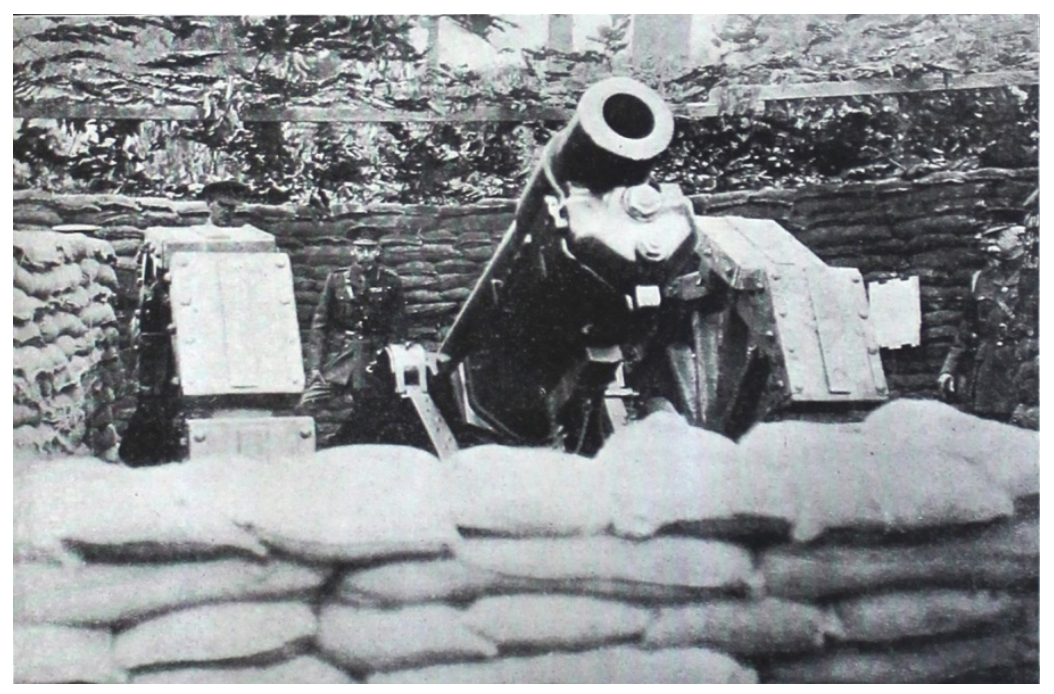

Fig. 4 - O rei de Inglaterra, Jorge V, visita as forças na frente de batalha, tendo sido fotografado junto a uma posição da artilharia britânica. Imagens 
como esta foram classificadas na categoria "ação política e político-militar" e procuraram propagandear a proximidade dos líderes, a sua participação no esforço de guerra, a sua legitimidade para tomarem medidas que levavam milhões à morte, bem como a coesão e comunhão entre os soldados e os seus líderes e governantes. O soberano britânico quase é "engolido" pela presença massiva da peça de artilharia, que sugere força e poder: poderia haver melhor fusão simbólica entre o poder político e o poder bélico? A fotografia é dos serviços oficiais britânicos (OfficialPhotographs Press Bureau).

Fonte: O Espelho, 9 set. 1916, p. 211.

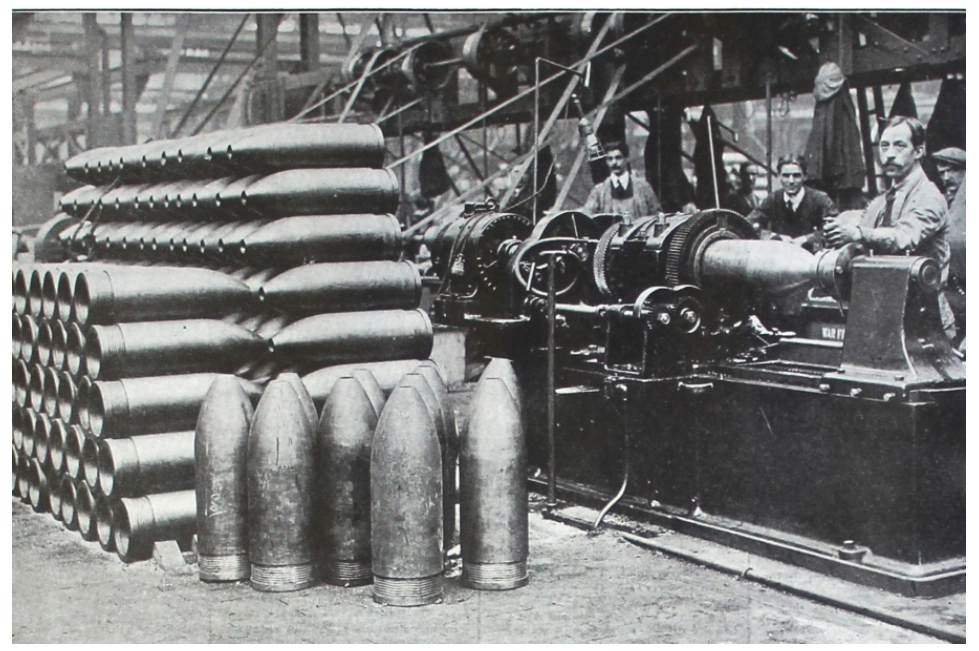

Fig. 5 - Fabrico de munições em Inglaterra. Exemplo de uma fotografia categorizada como "Vida civil". As fotografias alusivas ao esforço de guerra, ainda que informassem sobre as condições de produção de material de guerra, conotavam-se com as ideias de competência e de capacidade. Além disso, a propaganda britânica procuraria, com elas, demonstrar que toda a Inglaterra dava os seus melhores esforços na hora do combate.

Fonte: O Espelho, 9 set. 1916, p. 224. 


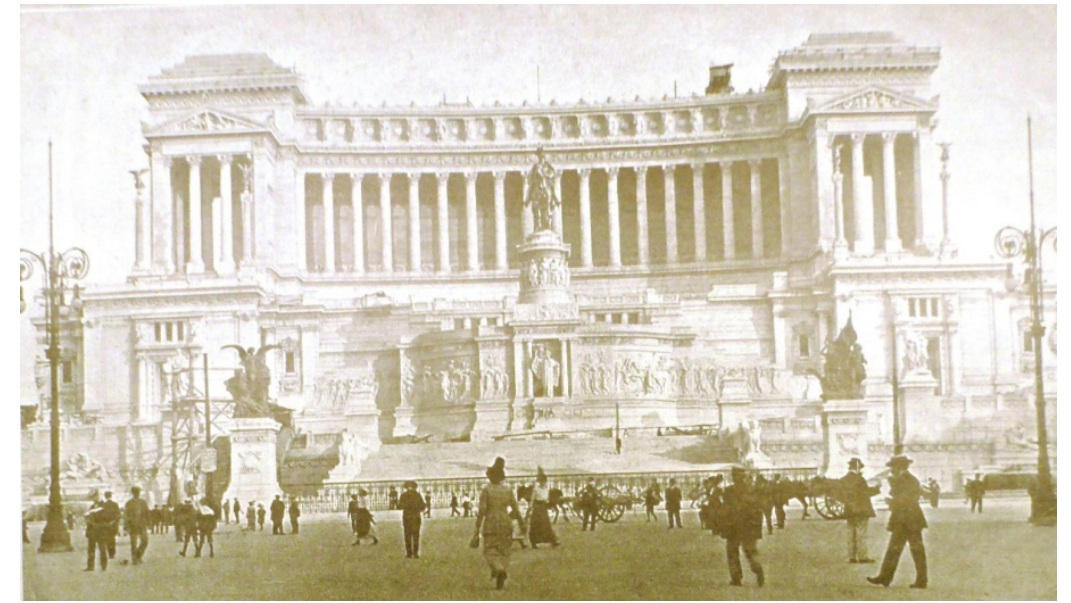

Fig. 6 - Na fotografia, o simbólico e impressionante monumento à unificação da Itália e ao rei Vítor Emanuel I, conhecido por Altar da Pátria, em Roma, classificado na categoria "Paisagens e edifícios". Imagens como esta foram publicadas n'O Espelho com a dupla finalidade de sinalizar textos sobre o que se passava em determinados lugares e de transportar os leitores para os lugares mencionados nos textos, permitindo-lhes ver sem estar lá. Teve também por objetivo valorizar simbolicamente os Aliados ao realçar o seu património cultural edificado.

Fonte: O Espelho, mar. 1916, p. 5.

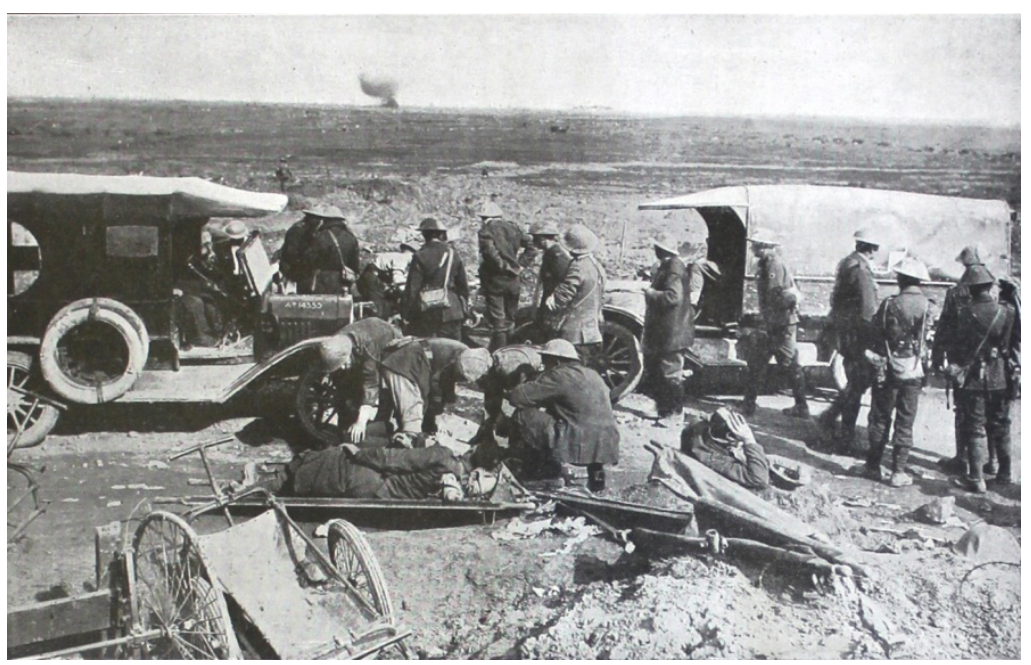

Fig. 7 - Imagens alusivas aos socorros aos feridos de guerra estiveram, também elas, presentes nas páginas d'O Espelho. Ao mesmo tempo que, de alguma maneira, mostram como se processavam esses socorros, nas suas várias 
fases, essas imagens sugerem, por um lado, que nenhum ferido seria deixado para trás; por outro lado, sugerem também que os combatentes aliados poderiam contar com bons socorros, em alto estado de prontidão, no caso de terem o infortúnio de serem feridos em combate.

Fonte: O Espelho, 30 dez. 1916, p. 350.
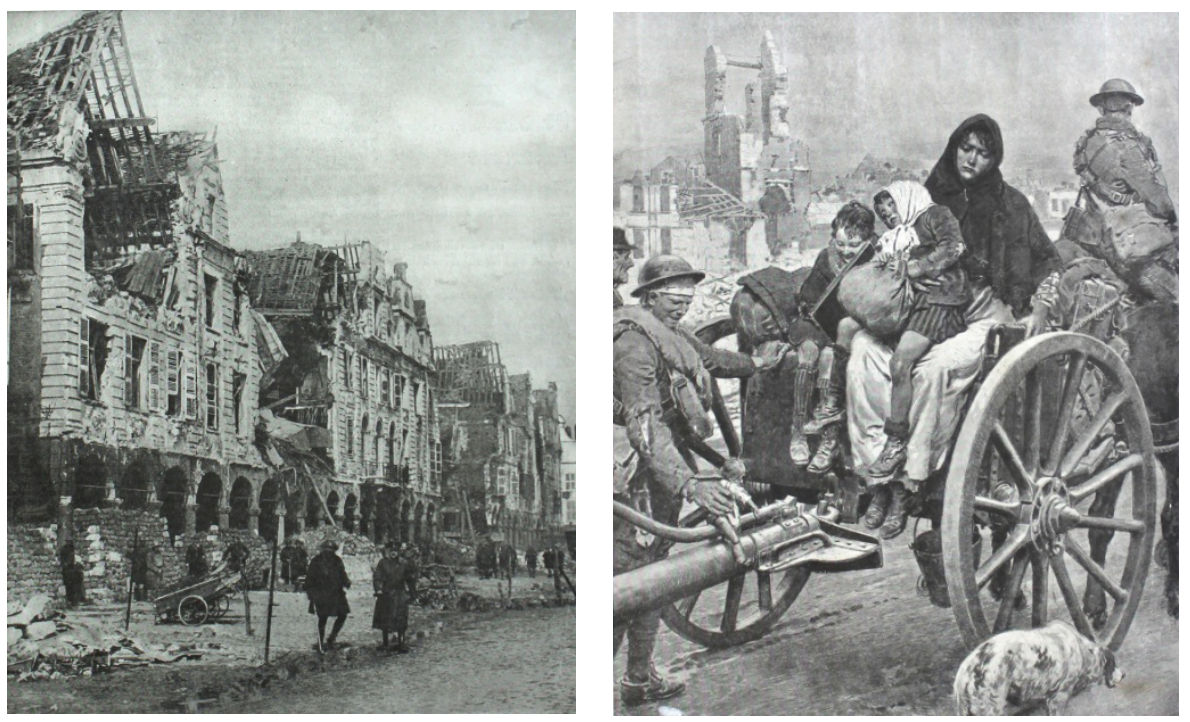

Figs. 8 e 9 - Ruínas da Grand Place, em Arras. Desenho intitulado "Apanhados pela onda da guerra - franceses fugindo das aldeias capturadas pelo inimigo". Exemplos de imagens classificadas na categoria "Destruição e dano provocados pelo inimigo". Todas as imagens dessa categoria procuraram demonstrar visualmente, sem exceção, a alegada barbárie alemã, compadecendo o leitor e tornando-o solidário com as vítimas desta barbárie. Por isso O Espelho publicou, frequentemente, imagens das vítimas inocentes da "crueldade germânica", muitas delas mostrando, em primeiro plano, mulheres, idosos e crianças, e até animais, aparentemente indefesos e deprimidos. A cena representada no desenho procura também explorar o tema do cavalheirismo britânico: o soldado, apesar de ferido, anima uma criança com um boneco.

Fonte: O Espelho, 16 jun. 1917, p. 116; 27 jul. 1917, p. 168. 


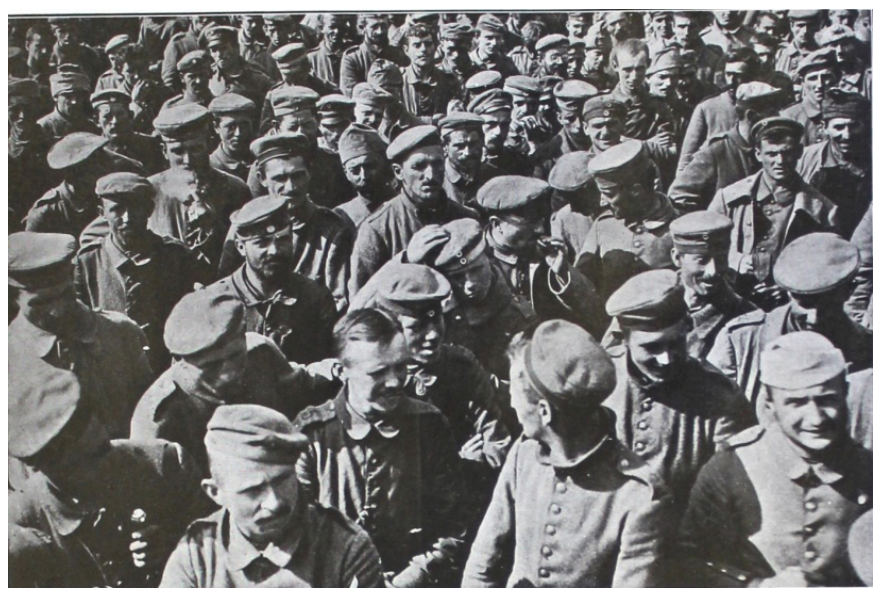

Fig. 10 - Fotografia de prisioneiros alemães, classificada na categoria "Destruição e dano provocados ao inimigo". Os prisioneiros alemães parecem descontraídos, conversadores e até sorridentes. A propaganda britânica aproveitava estes instantâneos fotográficos para, ao mesmo tempo, graças ao potencial de verosimilhança e testemunho das imagens fotográficas, provar que os britânicos estavam a ganhar a guerra ou, pelo menos, a infligir enorme dano à capacidade militar germânica; provar também que os prisioneiros alemães eram bem tratados e, quiçá, até estariam satisfeitos com a sua sorte, já que para eles a guerra teria acabado e talvez até fossem melhor tratados nos campos de prisioneiros dos britânicos do que nas suas trincheiras.

Fonte: O Espelho, 6 out. 1917. 


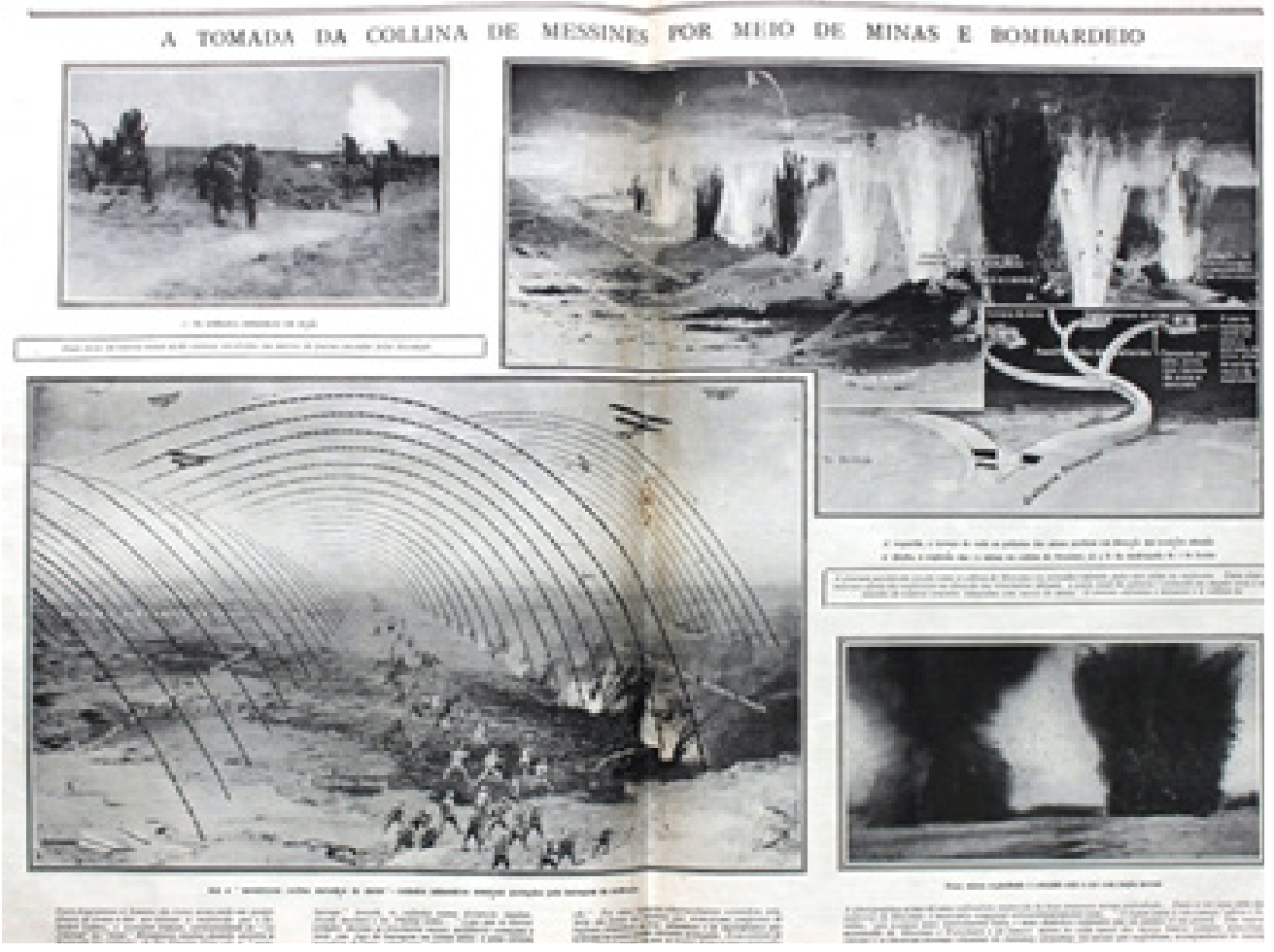

Fig. 11 - Um dos aspetos interessantes da cobertura da Grande Guerra protagonizada pel'O Espelho residiu na utilização de infografias como esta (publicada numa dupla página), alusiva à tomada de Messines aos alemães, graças à perfuração de minas por baixo das posições inimigas - que depois eram atulhadas de explosivos e feitas explodir - e aos bombardeamentos de artilharia. Muitos dos elementos estruturantes das infografias na imprensa estão presentes: textos, diagramas, fotografias combinam-se para explicar ao leitor as táticas de guerra que tinham dado uma nova vitória aos britânicos.

Fonte: O Espelho, 14 jul. 1917, p. 152-153. 